\title{
Articles
}

\section{Individual Variables, Literacy History, and ESL Progress Among Kurdish and Bosnian Immigrants ${ }^{1}$}

\section{Sheena Gardner, Eleoussa Polyzoi, and Yvette Rampaul}

This study examines the relationship between individual variables and ESL progress among nine Kurdish and seven Bosnian immigrants. All participants are adult refugees who arrived in Canada with virtually no English. Significant correlations are found between the dependent variables of oral and written progress and the independent variables of literacy level, years of schooling, and ethnicity. Contingency, text quality, and text quantity are also examined. Although the number of participants is small and the number of variables examined is large, it is hypothesized that in 18-21 months high literates will progress from low beginner to advanced, semiliterates from pre-beginner to low intermediate, and preliterates from pre-beginner to low beginner. The article concludes with implications for ESL programming and future research.

\section{Introduction}

The Canadian Census figures, based on self-reporting, and data from the Language Skills Used in Daily Activities (LSUDA) study, based on a performance test of functional literacy, suggest that gender, age, occupation, years of schooling completed, and country of origin are all significant variables in predicting proficiency in English (Klassen \& Burnaby, 1993). In particular, the adult English as a second language (ESL) literacy population-that is, those with minimal literacy skills in any language - " tends to include more women than men, they tend to be older, and to be outside of the labor force or employed in marginal sectors of the economy, [and] the difference in level of education attained is growing in comparison to the Canadian-born population" (p. 382). The 1981 Census suggests that immigrants who were born in southern Europe, Southeast Asia, and East Asia were more likely than other groups to speak neither official language (Klassen \& Burnaby, 1993, p. 379).

The individual variables cited in the Census studies are easily identifiable and quantifiable. They are thus readily available to those responsible for assessing and placing learners in ESL programs. Of these, ability to speak an official language is most obviously related to years of formal education (in any language) in the Census data. Pendakur (1992) reports that approxi- 
mately three quarters of the immigrants ( $72 \%$ for men and $81 \%$ for women) who reported the ability to speak neither official language had fewer than nine years of schooling and more than half had fewer than six years. In comparison, fewer than one quarter $(21 \%$ of men and $22 \%$ of women) of those who reported ability to speak an official language had fewer than nine years of education (Klassen \& Burnaby, 1993).

Although years of education correlate well with ability to speak English as a second language, a more precise guide is the learner's literacy history, which varies not only according to the level and nature of formal education, but also according to the role of literacy activities in the society of origin. If a learner comes from a literate society and has successfully completed 12 years of formal education, that learner is fully literate, whether in a Roman alphabet, as used by English or German, or a different writing system, as used by Chinese or Arabic or both. Semiliterates have some literacy skills in their mother tongue, but not enough for them to have confidence in tackling English literacy or to use literacy as an aid in learning the language. Nonliterates are not literate in any language, but come from a literate society. Preliterates are not literate in any language and come from a society or a section of a society where literacy plays little or no part in communication (Jones, 1990; Bell \& Burnaby, 1984). Years of formal education and information about the nature of the schooling will give the assessor an initial guide to literacy level. Often it will also be necessary to assess first-language literacy skills as described (Bell \& Burnaby, 1984). The consequences of not doing so are summarized by Wiley (1993).

Assessment all too frequently ignores a student's prior educational history in L1. Ignoring information about the L1 is functionally equivalent to repressing it. Also, ignoring information about lack of prior schooling disadvantages unschooled students when familiarity with classroom practices is expected. Because language proficiency is normally measured by school-based or school-like tests, entry L2 proficiency is largely a function of prior schooling - even more so if the student has formally studied EFL. (p. 427)

Within the literacy groups further distinctions can be made. For example, among Roman alphabetics a distinction can be made (based on the authors' experience and knowledge of school divisions such as elementary vs. secondary) between high, mid and low literates, corresponding to approximately $12+, 9-12$, and 6-9 years of successful formal schooling. A distinction might also be made between high and low semiliterates, corresponding to 3-6 and 0-3 years of successful formal schooling. Similar distinctions can be made for non-Roman alphabetics, with the recognition that an alphabetic writing system such as Arabic, will transfer more easily to English than an ideographic writing system such as Chinese. The starting point for each of these kinds of 
learners in terms of the literacy experiences they bring to the ESL classroom is different.

A similar refinement of categories is necessary from country of origin to ethnicity. Learners who come from a minority language group in their country of origin will have had significantly different literacy experiences than those who come from a dominant linguistic majority. "Language and literacy policies have been used coercively by dominant groups to suppress oppositional uses of literacy; to bar or restrict access to education, voting and economic participation; and even to restrict public speech" (Wiley, 1993, p. 422).

When a group of Kurds from Iraq came to Manitoba in June 1992 and a group of Bosnians in January 1993, all with virtually no English, the opportunity arose to examine the relative influences of prior literacy experiences on the learning of English. We knew from personal experience with learners that some Roman alphabetics who arrive with virtually no English can be fluent in spoken and written English in as little as two or three years. For many of the Kurdish speakers, however, two or three years after arrival their learning of English is only just beginning.

The objective of this study was to determine which individual variables best predict the rate at which different learners acquire English. The variables included are literacy level, ethnicity, gender, age, occupation, years of formal education, and other languages learned. It was expected that the results would shed some light not only on which factors affect the rate of ESL acquisition, but also on why some factors are significant and the nature and extent of their significance.

Other factors that are known to be important predictors include aptitude for language learning; motivation and goals; attitudes to English, learning English, and staying in Canada; confidence as a learner; previous or posttraumatic stress; family status; contact with native speakers of English; and current pressures or stresses including family, health, and financial concerns. These factors were addressed in the interviews, which focused on the learners' experiences coming to Canada, their experiences learning English, and their goals and motivation. The interviews are analyzed in detail in Gardner, Rampaul, and Polyzoi (1996).

\section{Method}

\section{Participants}

The 16 participants in the study had arrived in Manitoba as refugees from war-torn areas, following periods of up to several years seeking asylum and living in refugee camps. Their biographical data are provided in Table 1.

The classification of participants into literacy categories is based on years of formal education together with placement information and biographical 
Table 1

Biographical Data of Participants

\begin{tabular}{|c|c|c|c|c|c|c|c|c|}
\hline & Ethnicity & Gender & $\begin{array}{l}\text { Age on } \\
\text { arrival } \\
\text { in Canada } \\
\text { in years }\end{array}$ & $\begin{array}{c}\text { Home } \\
\text { occupation }\end{array}$ & $\begin{array}{l}\text { Formal } \\
\text { education } \\
\text { in years }\end{array}$ & $\begin{array}{c}\text { Other } \\
\text { languages } \\
\text { learned }\end{array}$ & $\begin{array}{c}\text { English instruction } \\
\text { before arrival } \\
\text { in Canada } \\
\text { in years }\end{array}$ & $\begin{array}{l}\text { Literacy } \\
\text { group }\end{array}$ \\
\hline 1 & Bosnian & Male & 30 & Civil engineer & 17 & German & 0 & High literate \\
\hline 2 & Bosnian & Female & 33.9 & Student & 16 & German & 0 & High literate \\
\hline 3 & Bosnian & Female & 30 & Biochemist & 16 & German & 0 & High literate \\
\hline 4 & Bosnian & Male & 41.5 & Economist & 16 & German & 0 & High literate \\
\hline 5 & Bosnian & Female & 29.1 & Salesperson & 12 & Russian & 0 & High literate \\
\hline 6 & Bosnian & Male & 21.7 & Blacksmith & 11 & None & 0 & High literate \\
\hline 7 & Bosnian & Male & 19.5 & Unemployed & 8 & Russian & 0 & Midliterate \\
\hline 8 & Kurdish & Male & 22.9 & Student & 8 & Arabic & 3 & Semiliterate \\
\hline 9 & Kurdish & Male & 23.9 & Student & 8 & Arabic & 2 & Semiliterate \\
\hline 10 & Kurdish & Female & 23.9 & Housewife & 7 & None & 2 & Semiliterate \\
\hline 11 & Kurdish & Male & 42 & Water driller & 4 & \multicolumn{2}{|c|}{ Arabic, Farsi, Urdu 0} & Semiliterate \\
\hline 12 & Kurdish & Female & 17.6 & Student & 4.5 & None & 0 & Nonliterate \\
\hline 13 & Kurdish & Male & 29.3 & Office cleaner & 0 & \multicolumn{2}{|c|}{ Arabic, Farsi, Hindi 0} & Preliterate \\
\hline 14 & Kurdish & Female & 26.4 & Housewife & 0 & Hindi & 0 & Preliterate \\
\hline 15 & Kurdish & Female & 37.9 & Housewife & 0 & Urdu & 0 & Preliterate \\
\hline 16 & Kurdish & Male & 45.4 & Farmer & 0 & Arabic & 0 & Preliterate \\
\hline
\end{tabular}

Note. The English instruction comprised nonintensive courses in refugee camps.

data. Participant number 11 had four years of schooling in Arabic, his second language. This was achieved when he was a young man in the army, where he was motivated and did well. The other semiliterates in the group had seven or eight years of schooling, but this schooling had been interrupted by war and instability in the country. Participant number 12 had four years of schooling as a child. Although she attended school and was thus exposed to literacy in the school environment, she appeared to be a nonconfident learner.

Where there is only one learner in a literacy category, additional variables make comparison unreliable: the midliterate attended classes for only one month; the nonliterate did not write the pre- or post-Writing Assessment. These two learners are also the youngest in the group, the only two who were under 20 when they arrived in Canada. The results, therefore, focus on the three distinct groups of six high literates, four semiliterates and four preliterates.

The high literates had an average of 15 years of formal education; the semiliterates had 7 years; and the preliterates had no formal education. The 
high literates had an average age on arrival in Canada of 31 years, the semiliterates of 28 , and the preliterates of 35 .

\section{Language Assessment Tools}

The Winnipeg No. 1 School Division Adult ESL Oral and Written Assessments relate to the curriculum, the objectives of which are specified primarily in settlement, functional oracy, and grammatical terms. The settlement objectives focus on themes such as the family, health, and housing, which are reintroduced in a cyclical fashion through the levels, and are integrated with the functional and grammatical objectives. The Adult ESL Program orientation thus includes elements of the Common Educational Core designed to "provide for all students a common set of educational experiences, including the development of basic literacy skills, a command of standard English, and an understanding of common cultural knowledge" (Wrigley, 1993, p. 452), and the Social and Economic Adaptation in its recognition of learners' needs to "acquire the skills and knowledge needed to be self-sufficient, to function effectively in society, to access services, and to integrate into the mainstream culture" (p. 454).

The Oral and Written Assessments, together with the Intake Form, constitute a placement test for the six literacy levels and 11 regular levels of classes in the Adult ESL Program. Learners are placed not only according to their oral linguistic ability, but also according to their literacy skills and ability to function in a literacy-based classroom. The Assessment is an indirect measure of language proficiency in two respects: First, the content assessed reflects program goals as they interpret the real-life needs of adult immigrant learners. For example, total scores reflect not only the ability to put verb roots into an appropriate tense and number, but also the ability to answer personal questions such as "When did you come to Canada?" The overall emphasis is on oral English for settlement purposes. Second, the method of assessment is classroom-based rather than real-life-based. Some questions are perfectly authentic (e.g., Where are you from?); some are display questions to which both assessor and participant know the answer (e.g., What is on the table?); and a small number are artificial (e.g., insert the correct preposition). The correlation between the test results and the ability of the learner to function outside the classroom has not been investigated, as is the case for many ESL programs and assessments across Canada (Cumming, 1995).

\section{Intake Form}

If learners are unable to answer the first three questions of the Oral Assessment, they are given the Intake Form and asked "What is this?" as the examiner points to 5 numbers, 5 upper case letters, 5 lower case letters, then 17 pictures. This is a measure of basic literacy as well as a measure of whether learners have acquired any basic vocabulary in English. 


\section{Oral Assessment}

Both the Oral Assessment and the Written Assessment increase in difficulty as the tests progress. The examiner takes the learner as far as he or she can go and then stops.

The Oral Assessment, or the Anna Test (Winnipeg School Division No. 1, Adult ESL Centre, September, 1991), is a structured oral interview that was developed from the original John Test (Language Innovations, Inc., 1976), and has been in use in various versions by Adult ESL at Winnipeg No. 1 since 1985. In a study of the Anne Test (a previous, similar version of the Anna test), McDonald (1986) found that there was a high split half reliability $(r=0.947)$. Earlier items did not discriminate well, but these were viewed as warm-up questions. Later items discriminated well ( $r=0.5$ to 1.0) for items that were average in difficulty ( $r=0.4$ to 0.75$)$.

The Anna Test has five sections: Section A contains personal questions such as "What is your name?" Section B contains questions on a picture of Anna and her family such as "What time is it?" and "Where is the book?" Section C contains more advanced personal questions such as "How long have you been in Canada?" Section D guides the learner to ask the examiner questions such as "What is your name?" Section E includes four open-ended questions. The first asks about leisure activities in the home country; the second asks for a description of a picture of an accident; the third asks for a comparison and contrast; the fourth asks about change in the nature of the family. Sections A to D are scored 3 for a perfect answer, 2 for a correct answer with some error of grammar or vocabulary, and 0 for an incorrect or no answer. One mark is deducted if the question has to be repeated, and this is noted by the score. Section E is scored for Vocabulary, Verbs, Structure, Complexity (e.g., compound or complex sentences), and Fluency.

\section{Written Assessment}

The Written Assessment consists of Forms A and B. Learners may either work through Form A to Form B, or start with Form B. Although it is called Written Exercise (Winnipeg School Division No. 1, Adult ESL Centre, June 1989), learners have to be able to read the texts and questions in order to answer them. The content is designed so that it is familiar to learners who have lived in places like Winnipeg. It contains a mix of personal topics and topics such as renting an apartment. The texts are varied from short passages to authentic-like texts such as ID cards and newspaper advertisements.

Form A, Section A asks the learners to write their names; Section B asks them to circle the correct time; Section $C$ asks them to copy the correct word under the picture; Section D asks them to label pictures; Section E asks learners to write answers to written personal questions such as "What country are you from?" Section $F$ asks learners to write answers to questions relating to new information given (a student card); and Section G asks 
learners to look at a picture of an immigrant family at home, read a short text about them, then answer written questions. Sections A to D receive one mark for a correct answer; Sections $E$ to $G$ are scored for Vocabulary, Verbs, and Structure, to a total of 3 per correct question.

Form $B$ is theme-based. It begins with the same picture as section $G$ of Form A, but with a different text about the same family, and four different questions. Section B is a text relating to the picture that has gaps for prepositions. All and only correct prepositions are provided in random order from which learners select. Section $C$ gives a newspaper advertisement and learners have to answer questions. Section $D$ is another passage with gaps, this time for verb tense where the roots are given. For Sections $E$ and $F$ there is a text with subheadings. Section $E$ is a multiple-choice vocabulary test, and Section F contains five written questions. Sections A, C, and F are scored for Vocabulary, Verbs, and Structure. Sections B, D, and E are scored one for each correct answer.

\section{Contingency Assessment}

As the scoring of the test does not isolate linguistic competence (e.g., ability to use correct prepositions, tenses, articles) from content, it was decided to isolate contingency to get a better sense of the learners' abilities to communicate meanings with or without correct grammatical support. The test interaction is generally of the question-answer form, so contingency is measured in terms of whether the answer has semantically appropriate and comprehensible content.

\section{Text Quantity and Text Quality Assessment}

A general sense of the quantity of the learners' answers is obtained by counting words and morphemes. It was hypothesized that the lower the level of English, the shorter the answers would be and the smaller the number of morphemes used.

A general sense of the quality of the learners' language is obtained by examining the content word:function word ratios. It was hypothesized that the lower the level of literacy, the more the learner would rely on content words (particularly nouns and verbs) in communicating; and, conversely, the lower the level of literacy, the less likely the learner would be to use function words (prepositions, articles, etc.).

\section{Procedures}

The principal measures of progress in English used in this study are the Oral and Written Assessments, which were administered when participants entered the Adult ESL Program and were then readministered as part of the posttest. At the time of the posttest, the high literates had been in Canada for an average of 18 months, whereas the semiliterates and preliterates had been in Canada for 21 months. The high literates had attended English classes for 
an average of 15 months (range 15-17 months), the semiliterates for an average of 13.5 months (range 12-17 months), and the preliterates for an average of 16 months (range 12-18 months). The classes met for 20 hours a week. Attendance by all participants was excellent, with the exception of the two preliterate women who suffered health problems. These absences are somewhat offset by the larger number of months spent by the preliterates in classes and in Canada.

\section{Intake Form Procedures}

The Intake Form was administered to all participants when they entered the program. In the posttest, all participants successfully completed the first few sections of the Oral Assessment, so the Intake Form was not readministered.

\section{Oral and Written Assessment Procedures}

The scores reflect how far a learner is able to go in the test. In the case of the writing, where most learners complete either Form A or Form B, if learners complete Form B, it is assumed for the purposes of the research that the learner would have scored all items on Form A correctly. Pre- and posttest totals were calculated out of the original 102 for the Oral and 118 for the Written, then converted to scores out of 100 for the purposes of comparison. For each language measure, $t$-tests, ANOVAs, and simple linear regressions were conducted using the following independent variables: literacy level, years of schooling, ethnicity, additional language(s) learned, age, gender, English courses before arrival in Canada, and months of English courses in Canada. Multiple regression analyses were considered but not conducted due to the problem of multicollinearity. For example, ethnicity is confounded with years of formal schooling and other languages learned. Also, multiple regression with such a small $n$ and eight independent variables is not recommended.

\section{Contingency Procedures}

Contingency scoring of oral responses was conducted for all questions in sections A, B, and C, a total of 16 questions. Sections D and E were not included because Section D asks learners to form questions, so it is not appropriate for contingency scoring, and most learners did not answer all of Section E. The scores reflect all 16 questions for 14 participants. Two preliterate participants are scored out of 14 as they did not answer the last two questions.

Contingency scoring of written responses was conducted for all appropriate sections, omitting items such texts with gaps and picture labeling. This amounts to a total of 29 questions across forms A and B, but as no one answered all the questions, the written contingency scores reported are as a percentage of the questions each individual answered. 


\section{Text Quantity and Quality Assessment Procedures}

The analyses of text quantity and text quality focus on the answers to four questions that are not routine, predictable questions and that cannot be fully answered from phrases given in the question or reading passage. Four oral questions best met these requirements. Two questions (B6 and E2) have the content of the answers determined by pictures; the other two draw on the learners' own ideas (C4 and E4). Questions E2 and E4 require long answers, whereas questions $\mathrm{B} 6$ and $\mathrm{C} 4$ can be answered in one or two sentences.

Initially we had planned to use mean length of utterance, which is a good rough measure of language proficiency, particularly at the beginning levels, as length of utterance increases with language proficiency (Allwood, 1993). The definition used by Allwood as "a stretch of uninterrupted speech produced by one speaker bounded by silence or by contributions from other speakers" (p. 133) was on the surface straightforward, but its application seemed problematic in that different interviewers appeared to have different interruption rates, and so a mean length of answer was used instead. For each answer, text quantity was measured in number of words and number of morphemes. Averages were calculated on questions answered.

For each answer, text quality was measured by content:function word ratio. Content words belong to the open-ended classes of main verbs, nouns, adjectives, and adverbs. All other words classes, such as auxiliary verbs, determiners, prepositions, and pronouns contain function words.

\section{Sample Procedure}

Table 2 shows how answers to question B6 were scored for contingency, mean length of answer and content word:function word ratio. These analyses were conducted only for answers on the posttest, as answers on the pretest were minimal.

\section{Results and Discussion}

Although the study is based on a small sample and the number of variables examined is large, the results are consistent with the experience of the authors and many ESL professionals who work with learners at various literacy levels. This study provides significant results that inform the role that literacy plays in the language learning process.

\section{Results by Literacy Group}

Intake Form Results

The results by literacy group are shown in Figure 1.

The results show that the high literates could identify numbers and letters as well as label pictures. This means that even before they started English classes, they had begun to acquire English for themselves. The relatively high score of the semiliterates shows that they did learn some basic English in 
Table 2

Text Analysis

Question B6: Where do you think the children will go tomorrow? (They are looking at a picture of a family and have just said that tomorrow will be Monday.)

\begin{tabular}{lcccc}
\hline $\begin{array}{l}\text { Sample answers } \\
\text { by fiteracy group }\end{array}$ & Contingent & $\begin{array}{c}\text { Answer } \\
\text { length in } \\
\text { words }\end{array}$ & $\begin{array}{c}\text { Answer } \\
\text { length in } \\
\text { mophemes }\end{array}$ & $\begin{array}{c}\text { Content: } \\
\text { function } \\
\text { word ratio }\end{array}$ \\
\hline $\begin{array}{l}\text { High literate } \\
\text { They will go to school. }\end{array}$ & Yes & 5 & 5 & $2: 3$ \\
I think the children will go tomorrow at school. & Yes & 9 & 10 & $5: 4$ \\
Semiliterate & Yes & 6 & 6 & $3: 3$ \\
I think they go to school. & Yes & 5 & 6 & $3: 2$ \\
The children go to school. & Yes & 5 & 6 & $4: 1$ \\
$\begin{array}{l}\text { Preliterate } \\
\text { Children Monday go to school. }\end{array}$ & Yes & 4 & 5 & $4: 0$ \\
Monday children go school. & & & & \\
\hline
\end{tabular}

Note. Content words are italicized.

their English classes that were held for an hour a day in refugee camps. The preliterates have an average of 5, largely because of one man who scored 15 where the others scored 3,0, and 2. Although he had no formal schooling, the

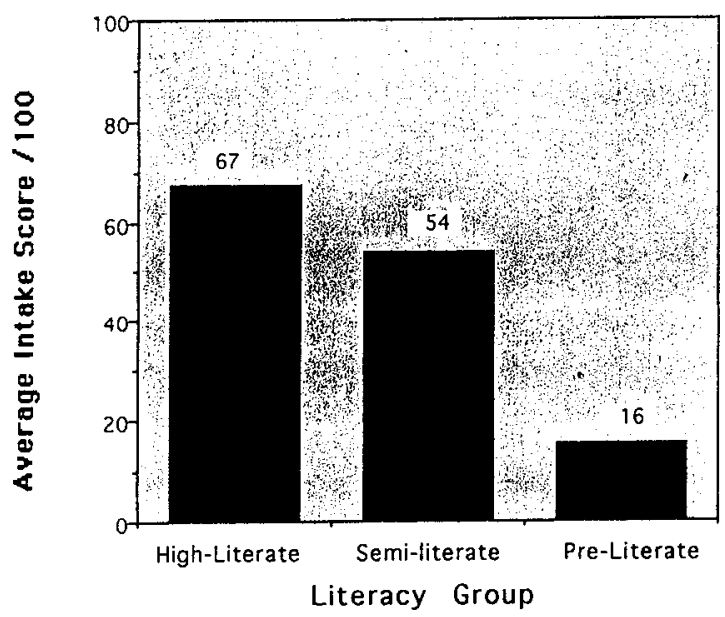

Note: Significant group differences $(F 2,11=11.212, p=.002$

Figure 1. Intake scores for each literacy group. 
man had worked as a cleaner in an office and had had more exposure to clocks and papers than the others who were housewives and a farmer.

\section{Results of Oral Assessment}

As shown in Figure 2, high literates perform better than semiliterates, who perform better than preliterates. This was the case for each section of the test as well as for the total. Furthermore, substantial progress has been made between the pre- and posttests in all sections. All started with low scores (10, 7 , and 1), and finished with 71,58 , and 43 for the high literates, the semiliterates, and the preliterates respectively. Thus the progress made by the high literates (61) is more than that made by the semiliterates (51), which is more than that made by the preliterates (42). In other words, the ranking of the groups relates not only to the literacy abilities of the learners initially, but also to the rate of their progress in learning oral English.

\section{Results of Written Assessment}

As the Kurds, with one exception, did not write the pretest, and, with three exceptions, did not complete Form B of the posttest, the results reflect not only performance on items answered, but also how far in the test the different groups were able to proceed. All three groups improved from 17, 0 , and 1 on the pretest to 91,48 , and 10 respectively on the posttest. Clearly, again, the difference in performance between the pre- and posttests is greater for the high literates than for the semiliterates than for the preliterates, as shown in Figure 3.

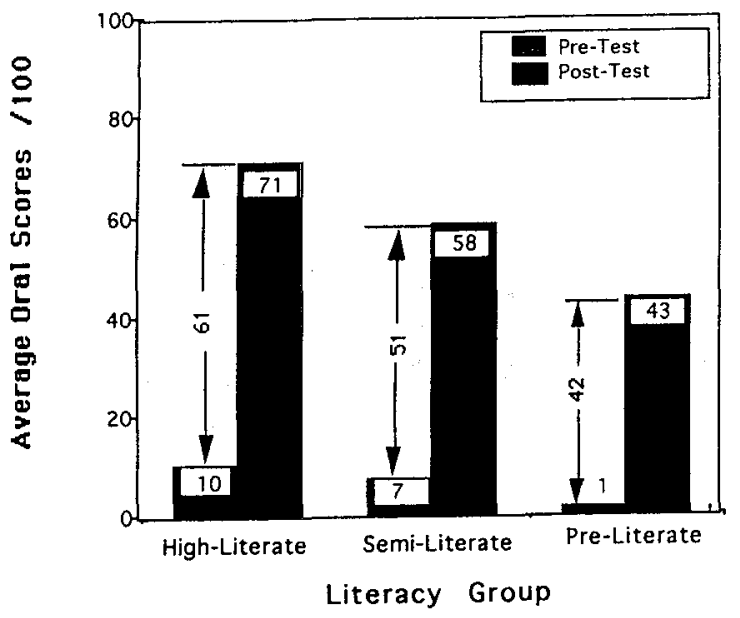

Note; Significant group differences for pre-test ( $F 2,11=4.322, p=0.04$ ), post-test $(F 2,11=15.912, p=0.0006)$, and difference scores $(F 2,11=10.76$, $p=0.0026$ ). Scores are rounded off to the nearest one.

Figure 2. Oral scores for each literacy group. 


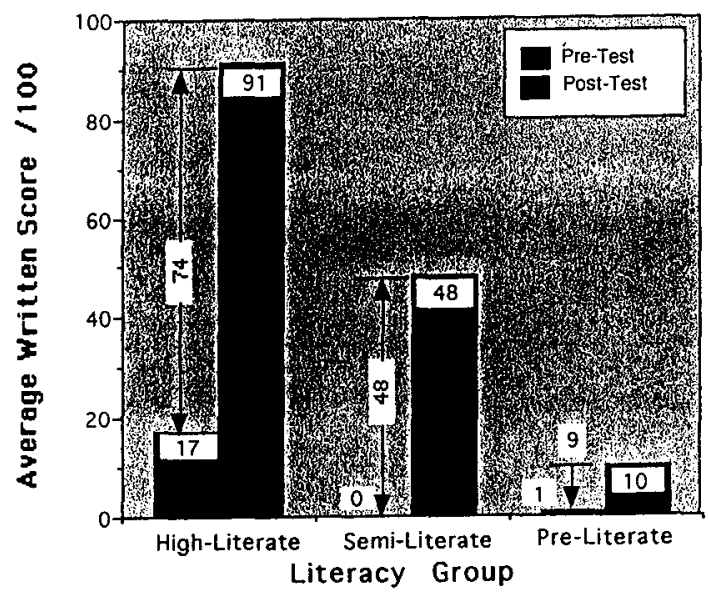

Note: Significant graup differences for pre-test $(F 2,11=42.104, p<.001)$, post-test ( $F 2,11=119.555, p<.0001)$, and difference scores ( $F 2,11=75.876, p<.0001)$

Scores are rounded off to the nearest one.

Figure 3. Written scores for each literacy group.

Comparison of Progress in Oral and Written Scores

Interestingly, as Figure 4 shows, there were significant within-group differences $(p<.0001)$ between the oral and written difference scores for both the high-literates and the preliterates. The high-literates, with high levels of schooling and well-developed first language literacy, are accustomed to learning through a written medium, even when the objective is spoken language. Thus their written skills improved more than their oral skills. In addition, their knowledge and experience of learning additional languages results from formal learning of Russian and German in schools, where the emphasis was on grammar and the written language.

In contrast, the preliterates' oral progress was significantly better than their written progress. They had no experience learning through reading and writing, so all their learning had been oral, informal, and experience-based. Similarly their previous language learning experiences were oral in context and survival-oriented.

The semiliterates, with little difference between their oral and written progress, show that they are capable of learning equally well through both informal, oral, and formal, written modes. They had experienced not only the formal learning of Arabic in school settings, with an emphasis on literacy, but also the informal acquisition of Arabic, which is the official language of Iraq. 


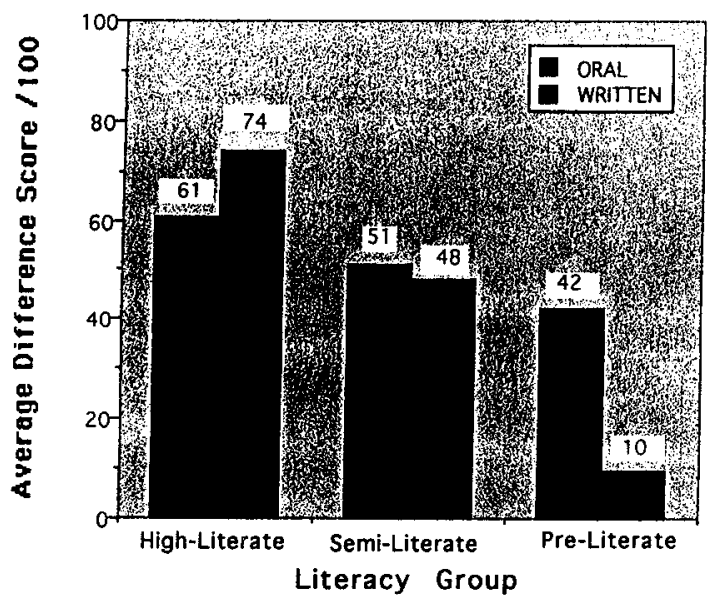

Note: Significant differences between oral and written improvement scores for High-Literate (t5=5.35, $p=.003)$ and Pre-Literate groups ( $t 3=10.008, p=.002)$, but NOT for the Semi-Literate group $(t 3-.563, p=.09)$.

Scores are rounded off to the nearest one.

Figure 4. A comparison of oral and written difference scores for each group.

\section{Contingency Results}

The results shown in Table 3 suggest that most of the participants were able to give a contingent response to most of the oral questions they answered, with the preliterates answering $85.25 \%$ contingently, the semiliterates answering $92.5 \%$ contingently, and the high literates answering over $98 \%$ contingently. A greater discrepancy is shown between the preliterates and the other groups for the writing where the preliterate learners responded contingently to $80 \%$ of the questions answered, whereas the other groups answered over $95 \%$ contingently.

As is observed in the description of question B6 above, all learners were able to give comprehensible and semantically appropriate answers to questions at their level.

Table 3

Percentage of Contingent Answers to Oral and Written Questions

Literacy group $\quad$ Oralquestions Written questions

$\begin{array}{lll}\text { High literate } & 99 & 96.38 \\ \text { Semiliterate } & 92.5 & 95.67 \\ \text { Preliterate } & 85.25 & 80\end{array}$


Table 4

Average Length of Words (ALW) and Morphemes (ALM) for Questions E2 and E4

\begin{tabular}{lcccccc}
\hline Literacygroup & \multicolumn{2}{c}{ Question E2 } & \multicolumn{2}{c}{ Question E4 } & \multicolumn{2}{c}{ Mean for E2 and E4 } \\
& ALW & ALM & ALW & ALM & ALW & ALM \\
\hline High literate & 73 & 87 & 91 & 105 & 82 & 96 \\
Semiliterate & 27 & 32 & 30 & 33 & 29 & 33 \\
Preliterate & - & did not attempt these questions & - & - & - \\
\hline
\end{tabular}

Results of Text Quantity Analysis

The first two questions required short answers, so there was little difference between the number of words or morphemes in the answers of each group. Table 4 shows, however, the great difference between the groups in terms of their ability to answer the more open-ended questions.

The high literates gave extended, complete answers and said significantly more than the semiliterates. The semiliterates were able to say a few sentences, but were not able to say all that they wanted to. The preliterates did not answer the questions because they had not been able to proceed that far in the test. Text quantity is an easy measure to calculate, and when used on answers to open-ended questions it can give an assessor a good initial measure of linguistic proficiency.

Results of Text Quality Analysis

The results of the content word:function word ratio analysis show that the higher the level of literacy, the greater the proportion of function words used, ranging from $26 \%$ among the preliterates, to $39 \%$ among the semiliterates, and $52 \%$ among the literates. Conversely, the lower the level of literacy, the greater the proportion of content words used, as shown in Table 5. Although increased use of function words might be expected with higher proficiency, interview data suggest that the three groups differed in their awareness of the role of function words and grammatical structure from the beginning (Gardner et al., 1996).

Table 5

Mean Content Word:Function Word Ratio as Percentage of Total Words Per Answer

\begin{tabular}{lccccc}
\hline Literacygroup & Question B6 & Question C4 & Question E2 & Question E4 & Mean \\
\hline Highliterate & $50: 50$ & $45: 55$ & $48: 52$ & $46: 54$ & $48: 52$ \\
Semiliterate & $60: 40$ & $62: 38$ & $62: 38$ & $60: 40$ & $61: 39$ \\
Preliterate & $82: 18$ & $65: 35$ & - & - & $74: 26$ \\
\hline
\end{tabular}


The first two groups have relatively consistent scores, that is, a narrow range, but the value of the preliterates' score lacks reliability because it is based on only two questions, the second of which was based on the scores of only two learners. It seems reasonable to assume that the percentage of function words would be less for the preliterates than for the semiliterates, but to determine how much less would require further analysis.

\section{Summary of Results by Literacy Group}

The results show that all participants have learned not only to perform in test conditions, but also to answer the basic personal questions that are drilled in many beginner level classes (Where do you live? etc.). This, together with an examination of the contingency, text quantity, and text quality of responses to Section E of the Oral Assessment and the later items on the Written Assessment, suggests that the learners' progress could be described as in Table 6. This description is not based on an established correlation between proficiency levels such as "intermediate" and performance on the Assessments. It is informed by a general understanding of the levels as they are used in the literature and in many different ESL programs, as well as the progress the participants made in the Adult ESL Program, where learners at the advanced level have the choice of general or TOEFL preparation classes.

On all measures, the high literates make more progress than the semiliterates who make more progress than the preliterates. In other words, the amount and kind of literacy skills learners bring will affect their learning.

In the next section we discuss the relationship between the other independent variables and the progress made by the participants.

\section{Results by Years of Formal Education}

Based on simple regression analyses, years of formal schooling was a significant predictor of intake scores $\left(t_{14}=3.24, p=.006\right)$, oral difference scores $\left(t_{14}=4.12, p=.001\right)$, pretest written scores $\left(t_{14}=7.21, p<.0001\right)$ and written difference scores $\left(t_{14}=5.98, p<.0001\right)$. The greater the number of years of schooling, the higher the language scores.

Learners with formal education bring much that can help them learn English in a classroom setting: well-developed literacy and oracy skills from

Table 6

Description of Progress made by Groups of Leamers in 18-21 Months

\begin{tabular}{|c|c|c|c|c|c|}
\hline Literacy & Oral & & Written & & Increase \\
\hline group & Pretest & Posttest & Pretest & Posttest & in levels \\
\hline High literate & Low beginner & High intermediate & Low beginner & Advanced & 8 \\
\hline Semiliterate & Pre-beginner & Low intermediate & Pre-beginner & High beg/Low int & $3 / 4$ \\
\hline Preliterate & Pre-beginner & Low beginner & Pre-beginner & Low beginner & 1 \\
\hline
\end{tabular}


the first language; a considerable amount of information about the first language system (e.g., how language functions); skills and learning strategies that allow them to use language to acquire new information and meet the demands of a classroom-based learning situation (e.g., using the dictionary, making notes, memorizing words or phrases); and a wide range of concepts on which to draw when confronted with new words in a second language (e.g., well-developed vocabulary base, knowledge of the world beyond their immediate environment, general knowledge on history, geography, politics, health, etc., adapted from Rampaul, 1995). In contrast, those with little or no formal education, or with negative experiences of formal education, find it harder to adapt to a classroom learning environment.

\section{Results by Ethnicity and Additional Language(s) Learned}

The Bosnians in this study clearly performed better than the Kurds. Based on a series of $t$-tests, there was no significant group difference on the oral pretest (they all started with virtually no oral English). However, there were significant group differences on the intake test $\left(t_{14}=2.4, p=.0308\right)$, the written pretest $\left(t_{14}=8.377, p<.0001\right)$, the oral difference scores $\left(t_{14}=4.987, p=.0002\right)$, and the written difference scores $\left(t_{14}=3.38, p<.0045\right)$. The difference between the Bosnians and the Kurds is probably due to a combination of factors: the Bosnian participants are literate in the Roman alphabet whereas the Kurds are either preliterate or literate in the Arabic alphabet; and the Bosnians have more years of formal education than the Kurds. Although literacy group and years of schooling are stronger predictors of progress than ethnicity, several reasons associated with ethnicity may have compounded the Bosnians' greater progress.

First, the Bosnian culture is European and closer to mainstream Canadian culture than the Kurdish culture, which is more Eastern. Second, the Bosnian participants came from a more urban environment, whereas the Kurds came from remote mountain villages, although some had spent time in refugee camps in larger towns and cities. The Bosnian infrastructure, institutions, and strategies for coping with the demands of modern life would prepare them better than the Kurds for North American city life. Third, the Bosnian participants were more able to build on their previous work experience and to adapt their occupational goals to the Canadian context. Consequently, most of them had found work or were studying with a professional goal in view. In contrast, many of the Kurds were making learning English and their children a priority.

Also related to ethnicity are the other language(s) the participants had learned and the conditions under which they were learned. Although there was no significant difference on the intake test or oral pretest scores between those who had learned German or Russian and the others, there were significant group differences on the written pretest $\left(t_{14}=6.79, p<.0001\right)$, the oral 
difference (improvement) scores $\left(t_{14}=3.675, p=.0025\right)$, and the written difference (improvement) scores $\left(t_{14}=2.597, p=.0211\right)$. Most Bosnians had learned German or Russian, both of which are closer to English than the Arabic, Hindi, Farsi, and Urdu reported by the Kurds. German and English are both Germanic languages written in the Roman alphabet. Russian and Serbo-Croatian or Bosnian are both Slavic languages written in the Cyrillic alphabet, although the Bosnian participants were more familiar with Bosnian in the Roman alphabet. Arabic is a Semitic language written in the Arabic alphabet. Kurdish and Farsi are Iranian languages, whereas Hindi and Urdu are Indic languages that the Kurds picked up orally on their journey to Canada. As previously mentioned, the Bosnians learned German and Russian as foreign languages in a classroom setting, whereas the Kurds learned Arabic as a second language through exposure and in some cases also in a classroom setting.

\section{Results by Age and Gender}

Large-scale studies report that "nearly one-third (32\%) of foreign-born women have extreme difficulty dealing with printed materials or can use printed words only for limited purposes ... compared to over one-fifth (24\%) of foreign-born men and approximately one-tenth Canadian-born men and women" and that such gender differences persist among immigrants who have completed secondary school (Boyd, 1991, p. 87, cited in Klassen \& Burnaby, 1993). In contrast, this study found no significant difference between the performance of men and women.

As with gender, age was not a significant predictor of either oral or written language scores, probably because there was little age variability among participants. That the preliterate learners are the oldest on average with the lowest scores is consistent with the observation that proportionally more older learners speak neither official language; however, among those in the Census who arrived more recently (1981-1986), the age spread has been more evenly distributed (Klassen \& Burnaby, 1993).

\section{Results by Length of Residence, English Classes before and in Canada} There was little variance in length of residence, months in English classes before coming to Canada, or months in English classes in Canada, and none of these was statistically significant. The Bosnians had generally been in Canada 18 months and the Kurds 21 months when they were reassessed.

The only participants who had had some English classes before they arrived were three semiliterates who had attended several years of nonintensive classes in refugee camps. The intake scores suggest that their ability to name some numbers and letters and to label some pictures was probably as a result of these classes. That they could not answer the first three questions on the Oral Assessment suggests that either they had not learned much, the 
accent was strange to them, or the stress of being tested inhibited production. It is probable that some passive knowledge or initial familiarity with the language contributed to their progress in Canada.

The scores of the one midliterate who only attended classes for one month on the Oral Assessment are consistent or perhaps a little lower than one might have expected had he continued in classes, but the content:function word ratio at $73: 27$ is as low as the preliterates. Similarly, his written scores are low, with a total of only 21 out of 100 on the posttest. In other words, there is some evidence to suggest that the English classes helped the others, particularly with the quality of the language and the written language, but the sample is far too small for this to be more than reasonable conjecture.

\section{Implications for Programming and Future Research}

The results of this study clearly support the hypothesis that learners with different literacy histories make significantly different progress learning English: high literates can reach an advanced level in the same time that semiliterates reach a low intermediate level and preliterates reach a low beginner level. In terms of programming, this means that learners will either move at different rates through the same program, or that different programs should be established for the different learners.

The results of this study also support the hypothesis that learners with different literacy histories learn differently: within groups high literates make significantly more progress in written skills; semiliterates make comparable gains in oral and written skills; and preliterates make significantly more progress in oral skills. This means that they tend to have different learning styles, based on their literacy history, as well as their past experience learning other languages: formal, literacy-based instruction versus combined formal instruction and exposure versus informal acquisition of the oral language. Such differences in learning style should be taken into account in programming.

Taken together, the results suggest that there is a need for three streams. This was indeed the Winnipeg No. 1 experience. The limited progress in literacy and oracy of the preliterate Kurds prompted the creation of special literacy classes in March 1993 and a Special Literacy stream in September 1993 for learners who have had no formal schooling, one or two years of schooling in a Roman alphabet, or three to four years of schooling in a non-Roman alphabet (Rampaul, 1994). This is proving beneficial for the learners and teachers.

Whether multiple streams are available or not, it is important for initial assessment to investigate learners' first-language literacy skills and their past language learning experiences in order to inform curriculum planning and classroom delivery. Learners should understand how and what the teacher 
expects them to learn. In most cases this will involve some first-language interpretation as well as access to bilingual grammars and dictionaries.

The results of this study also suggest many possible avenues for future research. The study might be replicated with a larger number of participants and with greater variation in age built into the design. Longitudinal studies to include assessment over different lengths of residence would also be informative. Measures might be used that correlate with recognized proficiency levels, such as the Benchmarks (Citizenship and Immigration Canada, 1996). A variety of assessment tools might be used, including more authentic assessment and a standardized test such as the Basic English Skills Test (BEST), which assesses the speaking, listening, reading, and writing skills of low-proficiency, non-native English speakers. Finally, curricula might be designed, implemented, and evaluated that focus not only on learners' needs and objectives, but that also accommodate learners' different past learning experiences.

\section{Note}

${ }^{1}$ This article is a later version of part of "Factors in Second Language Learning among Adult Immigrants" by Sheena Gardner, Eleoussa Polyzoi and Yvette Rampaul, presented at the TESL Manitoba/TESL Canada conference, Winnipeg, May 1996.

\section{Acknowledgments}

The authors would like to thank the University of Winnipeg for providing discretionary funding for this project; Brenda Beer and Hilda Wyenberg for assessing the participants; Khosrow Hakim-Zadeh and Simin Arefi for interpretation and translation; the Statistical Advisory Service, University of Manitoba for statistical assistance; Jeff Schellenburg and Cindy Reimer for research assistance; the anonymous TESL Canada Journal reviewers for their constructive feedback; and the Bosnian and Kurdish participants who generously allowed us to share in their learning experiences.

\section{The Authors}

Sheena Gardner and Eleoussa Polyzoi are associate professors in teacher education at the University of Winnipeg. Yvette Rampaul is Department Head at the Adult ESL Centre of Winnipeg. Sheena Gardner specializes in TESL and has worked extensively in the areas of assessment and progrannming for immigrants in Manitoba.

Eleoussa Polyzoi specializes in early childhood and special needs and has conducted extensive research on learners in bilingual programs as well as the quality of feedback provided by conversational partners of children in day care settings.

Yvette Rampaul has been actively involved in programming, materials development, and advocacy for ESL and ESL literacy adult immigrants.

\section{References}

Allwood, J. (1993). Type and quantity of feedback use as a measure of language proficiency. In

C. Perdue (Ed.), Adult language acquisition: Cross-linguistic perspectives. Volume I Field

methods and Volume II Results (pp. 133-144). Cambridge: Cambridge University Press.

Bell, J., \& Burnaby, B. (1984). A handbook for ESL literacy. Toronto, ON: OISE Press. 
Citizenship and Immigration Canada. (1996). Canadian language benchmarks: English as a second language for adults. English as a second language for literacy learners. Working document. Ottawa: Author.

Cumming, A. (1995). Changing definitions of language proficiency: Functions of language assessment in educational programmes for recent immigrant learners of English in Canada. Journal of the CAAL, 17, 35-48.

Gardner, S., Rampaul, Y., \& Polyzoi, E. (1996). Refugee experience, educational background and ESL: Lessons from learners. Unpublished manuscript.

Jones, S. (1990). Evaluation and assessment for ESL literacy. TESL Talk: ESL Literacy, 20, 294-304.

Klassen, C., \& Burnaby, B. (1993). "Those who know": Views on literacy among adult immigrants in Canada. TESOL Quarterly, 27, 377-397.

Language Innovations, Inc. (1976). The John test: A test of oral proficiency for ESL placement. New York: Author.

McDonald, M.S. (1986). A reliability study of the oral placement test, the Anna Test. Winnipeg, MB: Under review.

Rampaul, Y. (1994). Resource position for ESL literacy. Unpublished manuscript.

Rampaul, Y. (1995). Adult ESL literacy stream programming. Unpublished manuscript.

Wiley, T.G. (1993). Discussion of Klassen \& Burnaby and McKay \& Weinstein-Shr: Beyond assimilationist literacy policies and practices. TESOL Quarterly, 27, 421-430.

Wrigley, H.S. (1993). One size does not fit all: Educational perspectives and program practices in the US. TESOL Quarterly, 27, 449-465.

Winnipeg School Division No. 1, Adult ESL Centre. (1991). Anna Test. Winnipeg, MB: Author. 